\title{
Reflexões sobre as causas do declínio da reforma agrária no Brasil
}

Submissão: $13 / 08 / 2021$

Aceite: $25 / 09 / 2021$

Amilcar Baiardi ${ }^{1}$

Paulo Freire Mello ${ }^{2}$

Maria Thereza Macedo Pedroso ${ }^{3}$

\begin{abstract}
Resumo
O artigo analisa a redução recente das outorgas de lotes nos assentamentos implantados no Brasil pelo Instituto Nacional de Colonização e Reforma Agrária (INCRA). O trabalho se insere no campo conceitual da avaliação de políticas públicas e no tema da controvérsia científica, a partir de argumentos favoráveis e contrários à reforma agrária. A metodologia se utiliza tanto das evidências demonstradas pelos dados de áreas incorporadas para assentamentos, de números de outorgas de lotes, de indicadores de concentração e de demanda por terra, como da revisão da produção acadêmica sobre o tema. Como fontes utilizaram-se dados oficiais do INCRA e dos censos agropecuários do IBGE. Após análise das séries históricas e da exibição de argumentos de pesquisadores favoráveis e contrários à reforma agrária, são feitas considerações sobre as controvérsias e sobre as possíveis causas da diminuição do ritmo de famílias assentadas. Em continuação se admite que o debate em torno da Reforma Agrária não se esgotou e que a análise do seu declínio passe a integrar o mesmo. Finaliza com a constatação de que com ou sem reforma agrária recursos crescentes devem ser alocados para apoiar políticas voltadas para a agricultura de pequeno porte.
\end{abstract}

Palavras-chave: reforma agrária; assentamentos; concentração de terra; política agrária

\section{Reflections on the causes of the agrarian reform decline in Brazil}

\begin{abstract}
The article analyzes the recent reduction of the granting of production units in the settlements implanted in Brazil by the National Institute of Colonization and Agrarian Reform (INCRA). The work is inserted in the conceptual field of public policy evaluation and in the subject of scientific controversy, based on arguments favorable and contrary to agrarian reform. The methodology uses both the evidence demonstrated by the data from areas incorporated for settlements, the number of land grants, indicators of concentration and demand for land, as well as the review of academic production on the subject. Official sources from INCRA and from IBGE's agricultural censuses were used. After analyzing the historical series and showing the arguments of researchers in favor and against agrarian reform, considerations are made about the controversies and the possible causes of the slowdown in settled families. In continuation, it is admitted that the debate on Agrarian Reform has not ended and that the analysis of its decline will become part of it. It concludes with the finding that with or without agrarian reform, growing resources must be allocated to support policies aimed at small-scale agriculture.
\end{abstract}

Keywords: agrarian reform; settlements; land concentration; agrarian policy

\section{Introdução}

O objetivo do presente texto é analisar possíveis causas da redução das homologações de assentados pelo Instituto Nacional de Colonização e Reforma Agrária (INCRA) no Brasil. Na

\footnotetext{
${ }^{1}$ Pós-Doutorado em Políticas de Ciência e Tecnologia (IMSS, Firenze, Itália) e Doutorado em Ciências Humanas (UNICAMP). Professor do Programa de Pós-Graduação em Território, Ambiente e Sociedade, da Universidade Católica de Salvador (UCSAL). https://orcid.org/0000-0001-6087-5296 E-mail: amilcar.baiardi@gmail.com

2 Doutorado em Desenvolvimento Rural (PGDR/UFRGS). Servidor público do Instituto Nacional de Colonização e Reforma Agrária (INCRA). http://orcid.org/0000-0003-1361-5875 E-mail: pfreiremello@yahhoo.com.br

${ }^{3}$ Doutorado em Ciências Sociais (UnB). Pesquisadora da Empresa Brasileira de Pesquisa Agropecuária - Embrapa Hortaliças. http://orcid.org/0000-0002-7589-186X E-mail: maria.pedroso@embrapa.br
} 
prática, a interrupção ou o fim da reforma agrária. Após um auge de criação de novos assentamentos, de 1995 a 2010, as concessões de lotes de terra exibem diminuição significativa, chegando ao fim da presente década a números inexpressivos e aparente encerramento do processo. Entretanto, a queda do número de assentados não tem interferido no desempenho agregado da agricultura de pequeno porte, a escala de produção dos assentamentos. Diversamente do observado em passado recente, quando percepções de analistas do agrário brasileiro revelavam entusiasmo ou descrença com a reforma agrária, constata-se, presentemente, uma lacuna em relação às novas abordagens que iluminem as causas do ocaso do reformismo agrário, considerado, uma intervenção de envergadura para solucionar problemas econômicos e sociais. A agravar este quadro, ocorre o que Prigogine (2001) definia como paradoxo na ciência, divergências dando lugar a paixões, a subjetividades e irracionalidades.

O tema política de reforma agrária tem levado parte da comunidade de pesquisadores, talvez pelo que Kuhn, (1970) denominava imaturidade imanente às ciências humanas, a agir assim. É momento ultrapassar esse contencioso e tentar avaliar se a reforma agrária é ou não o único caminho para promover o desenvolvimento rural (Hoffmann, 2020). Embora o tema da reforma agrária tenha sido objeto de debates antes de 1964, medidas mais concretas e consequentes em termos do marco legal só aconteceram com o sancionamento da Lei no 4.504/1964 (Estatuto da Terra), permitindo a criação do Instituto Brasileiro de Reforma Agrária (IBRA) e do Instituto Nacional de Desenvolvimento Agrário (INDA), reunidos no INCRA em 1970. Desta forma, foi concebido e formalizado um aparato institucional sem o qual não seria possível o lançamento de um programa nacional de reforma agrária.

Entre os anos de 1964 e 1985, ano da posse de um presidente da República civil e do lançamento do I Plano Nacional de Reforma Agrária (I PNRA), esse aparato legal sofreu diversas reformas. A partir desse marco, outros fatos políticos influenciaram a política de reforma agrária, entre eles, a elaboração da Constituição de 1988 e as mudanças nas ações governamentais, desde o Governo Collor (1990-1992) até os dias atuais (Gomes da Silva, 1971; 1987; 1989) (Bruno, 2012) (Mattei, 2012).

A análise de política pública com objetividade se torna imperativa para se tratar a avaliação da reforma agrária, escoimando-a de juízos reducionistas e levando em consideração, contemporaneamente, duas posições muito claras. A primeira é defendida por Delgado (2005; 2014), que não dissocia Reforma Agrária da Questão Agrária. O autor entende ser conservadora a antinomia "reforma agrária" versus "modernização técnica", a qual emergiu no debate 
brasileiro após a democratização da vida nacional, com a chegada da Nova República. Para ele, é preciso separar os conceitos de terra mercantil e de terra como um bem social, também, tratados como "terra de negócio" e "terra de trabalho".

A segunda é a que propõe que Questão Agrária e Reforma Agrária são campos de análise e intervenção que nem sempre estão associados. Esta visão defende uma plêiade de políticas públicas de promoção do rural, ou políticas agrárias, que se colocam além do mercado, do liberalismo econômico, visando a valorização do rural. Esse conjunto de políticas não necessariamente viriam com a reforma agrária (Graziano Neto, 1994; 2004) (Navarro, 2014; 2016) (Navarro; Graziano Neto, 2015).

\section{Fundamentação teórica e método}

Quanto à natureza, o trabalho se caracteriza como investigação em ciências sociais aplicadas, com abordagem quali-quantitativa e via descendente hipotético-dedutiva, situandose no campo conceitual e epistemológico da avaliação de políticas públicas, no caso a política de reforma agrária, percorrendo, como etapas, sua gênese e seu desenvolvimento nos últimos 50 anos. Esta base permite estabelecer a rota analítica que integra a formulação, a racionalidade, o processo seguido e os resultados na forma de plano, programa e projeto de assentamento, visto como etapa final, cujo agregado oferece possibilidade de avaliação social e econômica e atribuição de um valor de eficácia comparativa. Nesta conduta, assimila-se o preceito de que a avaliação não deve se restringir exclusivamente aos resultados, mas incluir o desenho, a tomada de decisão e a implementação. Em outras palavras, o foco da avaliação está no julgamento entre o intencionado e o realizado (Trevisan; Van Bellen, 2008). Parte-se de supostos mais gerais da natureza e do papel de uma reforma agrária para avaliar os resultados alcançados, em uma perspectiva histórica.

Como método de procedimento, além da análise de séries históricas de dados, utilizouse a categoria controvérsia científica para ajudar a entender se o fim do processo reformista é um desfecho ideológico ou uma decisão política baseada em evidências de falta de eficácia, cotejada com a dificuldade crescente de implantação. Segundo Harry Collins (1981; 1992), a controvérsia científica é importante em análises históricas porque permite acompanhar o momento em que se tenta desconstruir um paradigma (conforme Kuhn, 1970) e sugerir a adoção de outro. 
Os procedimentos consistiram na revisão da literatura, no levantamento e análise de estatísticas oficiais e na contextualização de períodos, visando conferir mais objetividade ao texto, destituindo-o de narrativas que atribuíssem, exclusivamente, o declínio agrário reformista às mudanças nas percepções e preferências ideológicas dos propositores de políticas públicas. Finaliza, como recomendaria Popper (2000), com uma hipótese que instiga novas investigações, qual seja: o declínio da reforma agrária pode ser mais bem explicado pela baixa eficácia das intervenções, no cotejo com a crescente dificuldade de implementação, do que por mudanças de motivação ideológica relacionadas com a política agrária.

O trabalho inicia pela análise das séries históricas do número de famílias assentadas, as quais tiveram seu pleito por lotes homologados, e dos quantitativos de terra incorporados, dados que estão referenciados a períodos e à titularidade do poder executivo. Em seguida, analisa também as séries históricas do índice de concentração da terra e do número de estabelecimentos rurais sem área, de acordo com os censos agropecuários de 1985 a 2017. Na sequência procura qualificar a demanda por terra no Brasil e, a partir dela, questionar os métodos de fixação de metas de famílias a serem beneficiadas pela reforma agrária.

\section{A reforma agrária em números}

$\mathrm{Na}$ sequência apresenta-se as evidências numéricas acompanhadas de análise e contextualização do número de famílias assentadas, da demanda por terra e do índice de Gini da concentração fundiária.

\subsection{Famílias assentadas}

Durante cerca de 56 anos, em ritmos diferentes, mais acelerados a partir de 1995, se logrou outorgar assentamento para 1.372.172 famílias (INCRA, 2021). Mattei (2012), utilizando, também, como fonte os mesmos dados do INCRA, registra que, até 2010, em torno de 1.238.000 famílias foram assentadas. Tem-se, portanto, em quase uma década, uma desaceleração acentuada no número de famílias beneficiadas pela reforma agrária. Inequivocamente, percebese, segundo a tabela 1 , reduções acentuadas na área incorporada e no número de famílias assentadas, a partir de 2011. Na análise destes dados deve-se levar em conta que os assentamentos de um determinado ano resultaram de medidas legais e administrativas tomadas em anos anteriores. 
Segundo o INCRA (2021), vivem atualmente nos assentamentos 969.197 famílias, que correspondem aos lotes efetivamente existentes. Assim, a diferença de 393.975 em relação ao total da tabela 1 levou Mattei (2012) a supor abandono dos assentamentos. Entretanto, nem tudo é necessariamente abandono. Os dados contidos naquela tabela se referem a pessoas homologadas, o que inclui trocas por falecimento e desistência (Mello, 2016b). Numa mesma área pode haver sucessivas homologações.

Tabela 1 - Número de famílias assentadas por período de governo, 1979-2018

\begin{tabular}{|c|c|c|c|}
\hline Titular do Executivo & Período & Área Incorporada (1.000ha) & Famílias assentadas \\
\hline Governos Militares & Até 1984 & - & 18.500 \\
\hline José Sarney & $1985-90$ & - & 18.000 \\
\hline Fernando Collor & 1991-92 & - & 19.000 \\
\hline Itamar Franco & 1993-94 & $16.290 *$ & 11.000 \\
\hline Fernando Henrique & $1995-1998$ & 12.390 & 287.994 \\
\hline Fernando Henrique & 1999-2002 & 8.686 & 252.710 \\
\hline Lula da Silva & $2003-2006$ & 31.889 & 381.419 \\
\hline Lula da Silva & $2007-2010$ & 16.412 & 232.669 \\
\hline Dilma Roussef & 2011-2014 & 2.947 & 107.354 \\
\hline Dilma Roussef & $2015-2016$ & 234 & 28.021 \\
\hline Michel Temer & $2017-2018$ & 656 & 10.077 \\
\hline Jair Bolsonaro & 2019- & - & 5.428 \\
\hline Total & - & 89.504 & 1. 372.172 \\
\hline
\end{tabular}

Fonte: INCRA: Números da Reforma Agrária Execução Anual, Famílias Assentadas, Área Incorporada por Exercício (2020). ${ }^{*}$ Compreende a totalidade das áreas incorporadas até esta data

Observa-se que o declínio da reforma agrária, medida em números de assentados e em terra disponibilizada, tem início no quadriênio 2011-2014, com uma redução expressiva das terras incorporadas, que levou à magnitude de menos de $20 \%$ do disponibilizado no quadriênio anterior, 2007-2010. As áreas incorporadas, obtidas por arrecadação, desapropriação e compra, cuja disponibilidade se contraem expressivamente entre 2011 e 2014, passam, em 2015, a ter grandezas ainda menores. Tais magnitudes diminuíram de tal forma que a incorporação no biênio 2015/2016 foi reduzida a menos de 8\% da disponibilidade do quadriênio que se encerra em 2014 . Ou seja, antes da crise de 2014 observa-se um viés claro de conter e mesmo reduzir os investimentos a partir do quadriênio 2007-2010

Com base nos relatórios de gestão do INCRA, Mello (2020), constatou que os recursos anuais para desapropriação decrescem a partir de 2009, passando, em valores correntes, de $\mathrm{R} \$$ 740 milhões neste ano para praticamente zero uma década depois. O orçamento global do INCRA também se reduz, de $R \$ 3,3$ bilhões, em 2009, para $R \$ 2,2$ bilhões, em 2018. Segundo o autor, 
essa redução, contudo, não comprometeu os recursos para pagamento de pessoal (ativo e inativo) pois, no mesmo período, estes foram ampliados de $\mathrm{R} \$ 750$ milhões para $\mathrm{R} \$ 1,06$ bilhão. Mesmo admitindo limitações fiscais, a progressividade dos cortes orçamentários permite cogitar que se tratou de uma decisão no âmbito da política agrária, sem gerar reações que a revertesse. Outrossim, cabe considerar que a capacidade administrativa do INCRA não foi afetada pelos cortes orçamentários.

É necessário considerar que os critérios de outorga da terra não seguiam princípios técnicos baseados na viabilidade econômica do projeto de assentamento. Eram orientados por uma regra de valor máximo por família, a qual se manteve em cem mil reais por vários anos. A aplicação desse critério levava a que, dependendo do valor da terra e do bioma no qual o assentamento estivesse inserido, ser possível, ou não, outorgar uma área de lote suficiente para obtenção de uma renda mínima. Este raciocínio valia para todo o País, exceto para a Amazônia Legal, onde predominam terras públicas. A abundância de terras nessa região permitiu que metade dos assentados de todo o país estivessem localizados na região Norte, mesmo com uma demanda por terra menor, em função da infraestrutura precária e baixo dinamismo do entorno (Mello, 2016b). Acrescente-se o desincentivo relacionado à limitação legal de só ser permitido o cultivo de $20 \%$ da área.

Como explicar as causas dessa abrupta redução do número de outorgas durante o período 2011-2014? Obviamente que do lado do governo já era um efeito da crise fiscal, agravada pela valorização dos imóveis rurais decorrente do boom das commodities, em parte relacionado ao aparecimento da China enquanto grande compradora, assim como a inserção destas commodities no mercado financeiro. Este aquecimento do mercado de terra, embora não revele necessariamente uma correlação explícita com a entrada de investimentos estrangeiros diretos no país, sugere algum atrelamento dado os interesses do capital internacional em participar das cadeias do agronegócio (Flexor; Leite, 2017).

Ao mesmo tempo, o estímulo ao agronegócio também provocou a diminuição do assim chamado "latifúndio improdutivo," passível de desapropriação. Evidentemente que persistiam as áreas improdutivas, mas estas tendiam a serem rejeitadas pelo INCRA em decorrência de sua baixa qualidade. Além disso, entre as dificuldades para a aquisição de terra e as justificativas para fazê-lo, estariam as jurídicas, para a consecução de desapropriação e compra, e outras, tais como o decréscimo da demanda potencial e imediata por terras, o desempenho insatisfatório dos assentamentos e o ritmo das emancipações dos assentados nos mesmos (Graziano Neto; Navarro, 2015). 
Um aspecto curioso e relacionado com a inflexão acentuada de redução da área incorporada é que isso se dá no quadriênio 2011-2014, em um período governamental ao qual, a julgar pelo discurso oficial, não se pode atribuir falta de vontade política na execução da reforma agrária. A hipótese é que além da crise fiscal, da valorização da terra, da baixa performance econômica dos assentamentos e da permanente dependência do INCRA em termos de provimento de serviços, há algo não explícito publicamente que é um entendimento por parte dos policy makers de que o programa nacional de reforma agrária não oferecia um retorno social compatível com os investimentos realizados, uma percepção tecnocrática, que levou a progressivos cortes orçamentários. Neste momento, uma razão de Estado ${ }^{1}$ se impôs.

\subsection{A demanda por terras}

E como estaria a demanda imediata por terras? Quando se considera o número de famílias acampadas, de acordo com Carfantan (2020), constata-se um declínio acentuado. De 80 mil famílias em 600 acampamentos, no seu momento máximo, de 1996 a 2004, tem-se, nos tempos atuais, aproximadamente menos de cinco mil famílias acampadas em cerca de 50 acampamentos Tal decréscimo exerceria forte influência no declínio e paralisação da reforma agrária? Certamente que sim, mas isoladamente não explicaria o estancamento.

Já a demanda potencial por terra, que foi o principal indicador para definir as metas dos I e II PNRAs, jamais foi estimada com rigor. Nos primeiros anos de existência do INCRA, não obstante as características deste período da vida nacional, entre elas ausência de pressões por parte de agricultores sem-terra, o próprio órgão superestimava essa demanda por terra e defendia metas ousadas em termos do número de beneficiários. Na época, segundo Bruno (2012), falava-se em "reforma massiva", o que significaria, pelo menos, cinco milhões de famílias passíveis de serem assentadas. Nessa linha, segundo a revista da Associação Brasileira de Reforma Agrária (ABRA), porta-voz de pesquisadores, organizações sociais e defensores da reforma agrária, haveria 4,8 milhões de famílias sem-terra. Por outro lado, o I PNRA, 1985, elaborado por uma centena de estudiosos, definiu um universo de beneficiários potenciais de seis a sete milhões de famílias (Gomes da Silva, 1987) (ABRA, 2020).

A definição da meta de mais de seis milhões de famílias, sugere que os policy makers da época não se basearam nos dados da dinâmica populacional. Ocorria vertiginosa urbanização no

\footnotetext{
${ }^{1}$ Entenda-se razão de Estado uma capacidade do staff administrativo atuar com alguma independência em relação às pressões políticas.
} 
Brasil. A população urbana estava passando de $36 \%$, na década de 1950 , para $67,5 \%$, na década de 1980. Em 2010, ela se eleva para 84,36\% (IBGE, 2020a). Mesmo considerando a discussão de Veiga (2003), sobre o que efetivamente é população urbana, os números são contundentes.

Esse novo quadro impôs uma redefinição das metas da reforma agrária e o II PNRA de 2003 já não faz referência a milhões de famílias a serem assentadas. O que esteve no imaginário de alguns agraristas por décadas, nunca se tornou viável. Na realidade, se chegava a esses números mediante uma inadequada metodologia que, meramente, somava, com base nos censos agropecuários, o número de produtores rurais com menos de 100 ha, com produtores sem-terra e mais o número de arrendatários, parceiros e posseiros (Gasques; Conceição, 2000) (Graziano Neto, 2004).

O Censo Agropecuário de 2017 captou a dinâmica do crescimento setorial e aduziu dados que reforçam os argumentos na linha de redimensionamento das metas da reforma agrária, na eventualidade dela ser retomada. A perda de postos ocupados no meio rural, cerca de um milhão e 400 mil trabalhadores entre 2006 e 2017 - um fenômeno multideterminado que envolve, segundo Maia (2020), tanto aspectos estruturais da dinâmica da agropecuária como a atratividade pelo trabalho urbano - não aumentou a demanda imediata por terra. É o que sugere o fato de o número de estabelecimentos sem área própria haver diminuído de modo significativo no último período intercensitário, conforme a tabela 2.

Tabela 2 - Números de estabelecimentos sem área, 1985-2017

\begin{tabular}{lrrrr}
\hline Categoria & \multicolumn{4}{c}{ Censos Agropecuários } \\
& 1985 & $1995 / 96$ & 2006 & 2017 \\
\hline Estabelecimento com área & 5.793 .004 & 4.838 .183 & 4.920 .617 & 4.996 .287 \\
Estabelecimento sem área & 8.805 & 21.682 & 255019 & 77.017 \\
\hline Total de estabelecimentos & 5.801 .809 & 4.859 .865 & 5.175 .636 & 5.073 .304 \\
\hline Fonte: Censos Agropecuários 1985-2017 (IBGE, 2020b) & & &
\end{tabular}

O acesso à terra continua sendo uma conquista importante, mas ele não tem como único e exclusivo mecanismo legal a existência de algum programa oficial de redistribuição de terras. Segundo Gasques e Conceição (1997), a demanda de terra para a reforma agrária adotada pelo INCRA, é obtida de maneira substancialmente diferente da demanda econômica, que deve ser estimada a partir da identificação e quantificação do público a ser atendido. Não necessariamente de acordo com as relações que o produtor tenha com a terra e nem a partir de um arbítrio de qual deve ser a quantidade de terra necessária ao beneficiado. Para os autores, a quantidade de terra deveria ser determinada a partir de parâmetros que assegurem condições 
mínimas de distribuição de renda e de produção econômica. Da mesma forma, se deveria levar em consideração, também, o preço da terra, pois este tem impacto, tanto sobre a quantidade demandada quanto sobre o custo do programa.

O uso do índice de Gini para estipular as metas da reforma agrária também não faz sentido, pois os resultados podem conter distorções, a depender do número de imóveis ou de estabelecimentos agropecuários considerados em uma certa unidade de coleta. Por exemplo, se em um determinado município houver, hipoteticamente, apenas latifúndios do mesmo tamanho, o índice de Gini se aproximará do zero.

\subsection{A concentração fundiária}

Em que pese o expressivo número de produtores rurais assentados desde que a reforma agrária teve efetivamente início no país, o qual equivale a cerca de $20 \%$ do número de estabelecimentos agropecuários contabilizados pelo Censo Agropecuário de 2017, o ingente investimento que a sociedade brasileira realizou em reforma agrária, contrariando expectativas, não modificou o índice de concentração de terra no Brasil. A tabela 3 apresenta uma série histórica de quase um século de estimativas do índice de Gini. Nela se observa que durante o clímax de assentamentos, entre os anos de 1995 e 2010, medido em quantidade de área incorporada e em famílias assentadas, o índice de Gini permaneceu praticamente estático, oscilando de 0,857 para 0,858.

Tabela 3 - Brasil, evolução do índice de Gini sobre concentração fundiária, 1920-2017

\begin{tabular}{lcc}
\hline Ano & IBGE & INCRA \\
\hline 1920 & 0,798 & - \\
1940 & 0,826 & \\
1950 & 0,838 & 0,836 \\
1960 & 0,836 & 0,837 \\
1967 & - & \\
1972 & - & 0,854 \\
1975 & 0,855 & - \\
1978 & - & \\
1980 & 0,857 & 0,831 \\
1985 & 0,858 & \\
1992 & - & 0,843 \\
$1995 / 96$ & 0,857 & - \\
1998 & - & - \\
\hline 2006 & 0,858 & \\
\hline 2017 & 0,864 & \\
\hline
\end{tabular}

Fonte: Sparovek, 2003 (período 1920-1998) e Hoffmann 2020 (período 2006-2017). 
Conforme a tabela 3, há cerca de 80 anos não se registra nenhuma mudança sensível no índice de Gini para o Brasil, o que sugere que o grau de concentração de terra nos estabelecimentos agropecuários, conforme o Instituto Brasileiro de Geografia e Estatística - IBGE (2020b), ou nos imóveis rurais, conforme dados do INCRA, não tem sido um impedimento para a dinâmica econômico-produtiva da agropecuária nacional.

A seguir, apresenta-se uma seleção dos principais argumentos a favor e contra a reforma agrária, os quais ajudam a identificar as possíveis causas do bloqueio do ritmo reformista e dão amparo a conjecturas sobe se os motivos do declínio são mais bem explicados por razões ideológicas ou se refletem o reconhecimento de que a reforma agrária perdeu, ou nunca teve, eficiência diante do que se propunha.

\section{Prós e contras à reforma agrária}

\subsection{Em defesa da reforma agrária}

Entre pesquisadores defensores da vigência da Reforma Agrária, ou aqueles que, segundo Delgado (2005), não dissociam a Reforma Agrária da Questão Agrária, com risco de omissões, elegeu-se alguns que, a juízo dos autores, aduziam seus argumentos com maior clareza e menos subjetividade. O primeiro deles é Mattei (2014a), que, ao fazer uma análise das teses a favor e contrárias à reforma agrária, sistematiza as favoráveis em quatro tipos: dois deles se referindo ao nível de abrangência, seja territorial ou seja nacional; um terceiro com foco nos impactos sociais da reforma agrária; e um quarto tipo, com foco no caráter mais político, vendo a reforma agrária como um instrumento de combate ao latifúndio e indutor de reformas estruturais.

Após expor as teses contrárias à reforma agrária, Mattei (2014a) argumenta que, se por um lado, se pode relativizar o papel da reforma agrária como indutora de um amplo desenvolvimento agropecuário e agroindustrial, como colocado no debate em meados do século passado, por outro, não se pode negligenciar o fato de se ter um universo de 3.775.826 estabelecimentos agropecuários que são geridos por agricultores familiares, a grande maioria deles com pouca terra e que se encontram fragilizados.

Para Mattei (2014a) a "modernização conservadora" teria ensejado a expansão agrícola dentro de padrões empresariais, com exacerbação da desigualdade e da exclusão social. Nesta nova realidade, segundo o autor, estaria equivocada a ideia de que o capitalismo agrário do século XXI precisaria, apenas, intensificar o uso de tecnologias, uma vez que o aumento absoluto da produção não viria mais da incorporação de área ao processo produtivo agrícola. Isto porque 
a terra ainda teria centralidade no processo produtivo. Ademais, tal estratégia tecnológica não resolveria os problemas da exclusão social.

Avançando em seus argumentos, Mattei (2014a) associa-se a pesquisadores do rural que entendem que a reforma agrária ainda tem um papel importante a desempenhar nos rumos do desenvolvimento do país, especialmente em termos de auxiliar a equacionar o problema demográfico, bem como atuar tanto na esfera produtiva como na melhoria das condições sociais e econômicas das populações rurais fragilizadas. Mattei (2014a) defende que, não obstante as transformações ocorridas no meio rural, persiste uma questão agrária a ser resolvida para que se obtenha no país a democratização da propriedade fundiária. Ou seja, seria necessário combater as injustiças sociais e promover profundas mudanças como forma de inclusão de todos os segmentos populacionais, instituindo um processo reformador de caráter econômico, social, político e ecológico. Em complemento, Mattei (2014b) considera que ainda haveria uma alta demanda por terra, algo como três milhões de agricultores sem-terra ou com menos de cinco hectares, além de reafirmar que a terra ainda é um ativo de grande valor.

De forma semelhante, as análises de Silva (1998; 2013) apresentam a existência de um conjunto de fatores que teriam recolocado a reforma agrária no rol das opções de políticas públicas nesse início de século XXI. Em suma, crê que a reforma agrária criaria ocupação para uma parcela da população brasileira sem qualificação profissional e que, como parte da intervenção, ocorreriam investimentos em atividades não-agrícolas e serviços (viabilizando a outorga de lotes menores com menor custo), com absorção do excedente populacional, até que se complete a transição demográfica, já iniciada.

Um terceiro autor, Martins (2003), apresenta a intervenção reformista como tendo um amplo espectro de procurar reparar o passivo histórico, político e social do regime fundiário:

\footnotetext{
A questão agrária é, no Brasil, como em tantas outras partes do mundo, também uma questão política, pelo conjunto de interesses sociais e políticos que acumulou na definição e na sustentação das classes dominantes, particularmente os setores que expressam os interesses relativos à propriedade da terra. O Brasil tradicional e arcaico da dominação patrimonial, do clientelismo político, do coronelismo, é também um produto do regime fundiário e parte da questão agrária. Não fosse assim, a reforma teria sido feita e concluída há muito tempo (Martins, 2003 p. 171).
}

Nesta perspectiva, a reforma agrária teria uma função de criar novos atores que seriam, simultaneamente, aptos para atender suas necessidades alimentares e de renda via inserção em cadeias produtivas, mas também capazes de se diferenciar socialmente e politicamente como uma classe social não subordinada aos interesses fundiários. 
Barone e Botta (2013) acompanham essa argumentação e recomendam uma ressignificação da reforma agrária, no contexto brasileiro do Século XXI, mediante ações que visem ampliar a democracia, incentivar liberdades e enfrentar a altíssima concentração fundiária, característica estrutural do desenvolvimento agrário do país e inerente a uma modernidade anômala e inconclusa, geradora de desigualdades. Por fim, em Lacerda e Malagodi (2007), temse a reforma agrária como fortalecimento dos "camponeses" como classe social.

Uma outra visão, mais abrangente, radical e transformadora, é a de Marques (2011). A autora questiona os modelos de reforma agrária executados no Brasil, propondo que se vá além do caráter nacional uma vez que ele se encontra envolvido por um emaranhado de forças, atuantes em diversas escalas, as quais levaram à consolidação do regime alimentar corporativo e ao termo segurança alimentar em lugar de soberania alimentar, o qual implica ter domínio de todo o processo de produção, da semente ao produto final, em combate ao "agronegócio" e ao "autoritarismo do monopólio".

Este conjunto de perspectivas, extremamente resumidas aqui, propõe um alargamento da noção de questão agrária, onde, por exemplo, a democratização do acesso à terra é entendida como o processo de outorga de cidadania. Destacam também a busca por uma agricultura de base familiar, comunitária, agroecológica e com vocação para produção de alimentos "limpos". Destarte, à reforma agrária caberia a função econômica suplementar de fomentar o desenvolvimento rural das regiões com menor dinamismo econômico e de quitar a chamada dívida social, resultado da exclusão social gerada pela modernização conservadora.

Para além da ideia-chave de uma reforma agrária clássica, relacionada ao cumprimento das funções da agricultura no processo de desenvolvimento da economia de um país, em algumas proposições ela estaria ao lado dos projetos mais utópicos, de superação do próprio modo de produção capitalista e em direção a estilos de vida voltados à preservação ambiental.

\subsection{Questionando a reforma agrária}

De outro lado, alguns estudiosos dos processos sociais rurais no Brasil, divergem quanto à necessidade de continuar com a política de assentamentos. Sugerem que se cogitem outras medidas para redução da desigualdade e combate à pobreza no campo. Tais pesquisadores foram escolhidos também pela clareza de argumentos e representatividade das suas afirmações.

O pioneirismo no defender o cancelamento da política agrária baseada em metas de número de assentados, cabe a Graziano Neto (1989; 1994). O autor alega dificuldades orçamentárias, jurídicas e grandes inconsistências dos PNRAs no que concerne à definição e 
quantificação dos beneficiários, ao lado de razões econômicas e entendimento de que houve baixo impacto social nas intervenções realizadas. Questionava, já na década de 1980, a necessidade da reforma agrária como acicate à produção, ao consumo ou mesmo como instrumento de redução da exclusão, da desigualdade no campo e outorga de cidadania. Segundo ele, tal política deixara de fazer sentido e justificá-la como uma necessidade meramente ética, com vistas a universalizar direitos e promover justiça social, seria reducionismo, ao mesmo tempo que descarte de outras políticas públicas mais adequadas para tal finalidade.

Para o autor, os movimentos sociais que apoiam a reforma agrária são beneficiários indiretos dela na medida em que a convertem em uma estratégia de sobrevivência política. Ademais, insiste Graziano Neto, o seu uso como forma de integrar os marginalizados rurais aos circuitos econômicos e sociais não faria sentido, pois, haveria políticas públicas menos traumáticas e custosas (Graziano Neto, 1989; 1994).

Posteriormente, Graziano Neto (2004), rediscutiu a impropriedade da reforma agrária com a crítica do que chamou de velho paradigma agrário, referindo-se ao latifúndio como um fantasma que já não assustava. Igualmente, questionou a qualidade dos assentamentos e referiuse às adversidades dos assentados que já têm terra.

Dez anos após, Navarro (2014) reforçou os argumentos de Graziano Neto, afirmando que “a reforma agrária nunca existiu e nem existirá" (Sic), na medida em que não expropriou latifúndios, como se esperaria de uma reforma agrária clássica. Antes, o autor já havia destacado alguns equívocos da reforma agrária e problematizado a persistência da questão agrária no mundo rural (Navarro, 1997; 2011), questionando se a reforma agrária ainda faria parte de um rol de temas permanentes e irremovíveis da ação governamental. Isto porque as mudanças econômicas e produtivas correspondentes à nova fase de nossa história agrícola, assim como a aceleração de processos sociais específicos, teriam sepultado a questão agrária brasileira. E, não obstante a expressiva magnitude dos números apurados na execução de tal programa, ainda assim a distribuição de terras não causou nenhum impacto significativo sobre os índices de concentração da terra (Navarro, 2014).

Na mesma obra, este autor considerou falso afirmar que não haverá democracia no Brasil sem reforma agrária, pois, se existe uma relação de causalidade, nesse caso, seria à inversa, uma vez que a maioria das experiências internacionais de reforma agrária somente ocorreram em conjunturas políticas de regimes fortes e autoritários. Em complemento, sugere que a questão agrária, no âmbito da tradição teórica e política marxista, representou uma série sequencial e cumulativa de erros interpretativos, levando a reforma agrária brasileira a crescentes impasses. 
Dentre eles, o mecanismo da desapropriação tornou-se cada vez menos usado em face de impedimentos legais, forçando o Governo Federal a recorrer, com frequência, ao mecanismo de aquisição de imóveis, passando a ignorar a desapropriação por interesse social, em face da raridade de tais estabelecimentos ante a modernização produtiva.

Para além do contexto brasileiro, Navarro (2014) procura demonstrar que de um assunto candente no plano internacional do pós-guerra, até a década de 1970, a reforma agrária esmaeceu politicamente nas décadas posteriores, quando sua aparente necessidade social foi deixando de ser manifesta (Navarro, 2014).

A convergência interpretativa de Navarro e Graziano Neto (2015) se deu na publicação de o "Novo Mundo Rural", no qual, novamente, destacam o fato de que a dinâmica do crescimento do setor agropecuário esvaziou as razões, os motivos, tanto econômicos como sociais, para manter a agenda da reforma agrária na contemporaneidade do Brasil. Por fim, Navarro (2016), reafirma a inviabilidade econômica, a falta de demanda por terra, a dinâmica demográfica no meio rural e outras razões, para que a reforma agrária se ausente das políticas públicas.

Paulo Freire Mello é um terceiro autor a questionar a relevância da manutenção da reforma agrária no Brasil. Diferentemente de Graziano Neto e Navarro, que basearam suas conclusões em análises teóricas e avaliações de tendências em grandes agregados de dados, Mello (2016a; 2016b) constrói seus argumentos com base em pesquisas de campo por ele conduzidas. Inobstante uma diferente trajetória epistemológica, indutiva e ascendente, este autor, como os anteriores, defende que a reforma agrária clássica perdeu significado no Brasil. Isto teria ocorrido, como sugerem Maia (2020) e Hoffmann (2020), em decorrência do desenvolvimento da agropecuária nacional nas últimas décadas ter influenciado a dinâmica demográfica, modificado a demanda por terra e criado atraentes oportunidades de sobrevivência fora dos assentamentos. Destarte, Mello (2016a; 2016b), conclui que a reforma agrária teria perdido eficiência para combater pobreza e desigualdade no campo.

As análises de Mello (2016b) cobriram tanto estudos econômicos sobre assentamentos elaborados por vários pesquisadores, estudos estes considerados por ele pouco abrangentes, desatualizados e com problemas metodológicos, como as pesquisas internas realizadas pelo próprio INCRA, as quais geraram dados agregados sobre produção e renda dos assentamentos ao nível nacional, números estes que revelam baixa performance econômica dos beneficiados pela reforma agrária, em que pese em alguns lotes, se constatasse eficiência produtiva.

Mello (2016a; 2016b) concluiu pela alta incidência de pobreza e desigualdade dentro dos assentamentos, sendo que, no Nordeste, na Bahia precisamente, o quadro se mostrou muito 
mais grave que no Rio Grande do Sul. Assim, nestes estados, a renda agrícola nos assentamentos alcançou 14\% e 52\%, respectivamente, da renda esperada (definida pelo autor em 13 saláriosmínimos por Unidade de Trabalho Humano por ano). Nos assentamentos da Bahia, 25\% das famílias estavam na extrema pobreza (na época, auferindo até $\mathrm{R} \$$ 70,00/pessoa/mês), considerando os rendimentos totais (renda agrícola + renda não agrícola + outros rendimentos). Quando se considera somente a renda agrícola, 68\% estava em extrema pobreza. Isto porque, ali, a renda agrícola representava somente $26 \%$ dos rendimentos totais (Mello, 2016b).

Mello (2016b), esclarece que do ponto de vista econômico os assentamentos baianos se assemelham aos do Norte e Nordeste, onde está a grande maioria das famílias assentadas pelo INCRA Os trabalhos também constataram que a renda não tinha correlação positiva com a escolaridade e com o tamanho do lote, sendo estes sempre maiores no bioma caatinga, na área do Semiárido, área geográfica socialmente deprimida. As pesquisas constataram também que em ambos os estados, Bahia e Rio Grande do Sul, a assistência técnica era universalizada.

Para tentar explicar o relativo fracasso econômico dos assentamentos (mesmo considerando o sucesso de um grupo minoritário), o autor contraria tese compartilhada por alguns pesquisadores, entre eles Carfantan (2020), Ribeiro et al (2011), David et al (1998) e Ferreira (2013), que atribuem o insucesso da maioria dos assentamentos à falta de experiência em práticas agrícolas por parte dos assentados, fruto de uma origem não agrícola, essencialmente urbana. Mello (2016a; 2016b) não encontrou evidência empírica que confirmasse esta hipótese. Ao contrário, identificou, em assentamentos no Semiárido da Bahia, que a renda agrícola dos assentados que informaram não ter experiência prévia como produtor rural foi maior do que a do grupo que afirmou tê-la. No Rio Grande do Sul, observou, em um quadro de elevada amplitude de renda dos assentados em um mesmo assentamento, que os casos, tanto de renda alta como de renda baixa, independiam de as famílias serem oriundas ou não de municípios essencialmente rurais.

Os argumentos a favor e contra a reforma agrária ampliam a capacidade de entender e ponderar uma série de medidas que provocaram a paralisação dos assentamentos.

\section{Aparentes razões da paralisação da reforma agrária: resultados e discussão}

Um conjunto de normas legais passaram a condicionar os assentamentos a partir de 20172018, quais sejam: i) a determinação dos Acórdãos TCU no 775/2016 e no 1976/2017, que suspenderam cautelarmente os processos de cadastro e seleção de novos beneficiários para o 
PNRA e de novos pagamentos e remissões dos créditos instalação, bem como, o acesso a outros benefícios e políticas públicas atrelados à reforma agrária; ii) a Lei no 13.465/2017, que atualiza a Lei no 8.629/1993, que trata da reforma agrária e regularização das ocupações em estados da Amazônia pelo Programa Terra Legal; iii) o Decreto 9.311/2018, que regulamentou a Lei no 8.629/93 e a Lei no 13.001/2014, dispondo sobre a seleção, permanência e titulação das famílias beneficiárias do PNRA e iv) o cenário de restrição fiscal, refletido na redução das dotações orçamentárias (INCRA, 2021).

São normas tipicamente de Estado, podendo ser vistas como uma espécie de compliance corporativo, algo que teria que ser feito para preservar a imagem do INCRA. Com exceção da primeira que decorre da constatação de delitos, as demais sugerem que se mudaria de foco: em lugar de novos assentamentos, regularizar a posse da terra nos que foram criados e das posses fora dos assentamentos.

A contribuir para esta percepção por parte do INCRA há um grupo de publicações com três focos distintos, mas com interface entre eles. No primeiro foco, que se relaciona com a qualidade de vida nos assentamentos, Almeida et al (2009) se referem às falhas de implantação relacionadas à infraestrutura, financiamento, assistência técnica e supervisão, as quais devem ser atribuídas a problemas de gestão. Por exemplo, a Assistência Técnica e Extensão Rural (ATER), um serviço que era prestado ao INCRA via terceirização, apesar de sua indiscutível importância na consolidação de assentamentos, teve sua eficiência questionada. Os questionamentos se dirigiam aos baixos valores pagos, aos constantes atrasos nos repasses de verbas, aos problemas de infraestrutura e de seleção dos técnicos e à falta de fiscalização.

Mello (2020) também aduz elementos para entender os problemas de prestação de serviços em ATER. Para o autor, processos clientelistas dificultavam que os dirigentes do INCRA cobrassem das prestadoras de ATER resultados mais qualificados. Vale dizer que, a partir de 2011, os valores por técnico cresceram substancialmente, sem que se alcançassem melhores resultados. O programa deixou de existir em 2017, sem que se tenha atendido mais do que $40 \%$ dos assentados brasileiros (Mello, 2020).

Convém lembrar que, na escala nacional, a comparação dos Censos Agropecuários de 2006 com 2017, revela que o nível de atendimento dos estabelecimentos agropecuários brasileiros com ATER, se reduziu de 22\% para 20\% (IBGE, 2020b). Anteriormente, Alves; Santana e Contini (2016) constataram que os gastos com extensão rural a partir de 2003 não foram substancialmente diferentes dos anos anteriores, ou seja, ambos em níveis baixos. 
Um segundo foco, se situa nas relações de poder e de tomada de decisões no âmbito dos assentamentos, as quais têm dificultado a gestão dos mesmos. Nesse foco, Mello (2017, 2019a, 2020) aponta para o que ele denomina processos sociológicos relacionados com: (1) certa desatenção às questões de poder nos assentamentos e no espaço de mediação, privilegiando-se as decisões de um grupo ligado às "organizações de base"; (2) dificuldades de convivência social, redundando em conflitos, como aqueles decorrentes de imposições coletivistas, que não são aceitas por uma parte dos assentados, aspectos já assinalados por Marques (2000) e Alentejano (2018).

Em pesquisas com abordagem etnográfica, Mello (2016b; 2020) identificou dissintonia entre o ideário coletivista e grande parte das comunidades dos assentamentos, ideário esse com raízes na orientação leninista das organizações políticas e na adesão de parte da burocracia a uma visão "high modernist", no sentido descrito na obra de Scott (2020). ${ }^{2}$ Por fim, (3) excessivo foco da ATER e das parcerias do INCRA - envolvendo ações em assentamentos e o Programa Nacional de Educação da Reforma Agrária (PRONERA) - na pauta da agroecologia, não angariando apoio da maior parte dos agricultores (menos predispostos ao risco e às baixas produtividades que isto implica) e não conseguindo acumular conhecimento relevante, de modo geral. Segundo os relatórios do INCRA, de 2008 a 2018, foram dispendidos 2,32 bilhões em convênios, grande parte, de acordo com esta orientação, sem que se tenha procedido qualquer análise de impacto (Mello, 2020).

Como terceiro foco, Mello (2016a) argumenta que as vicissitudes enfrentadas pelos assentados não são diferentes daquelas dos demais produtores rurais que fazem a gestão de estabelecimentos agropecuários de pequeno porte econômico: sem ATER, sem qualificação técnica, sem escala para lidar com o mercado, barganhando menor preço na aquisição de insumos e sendo tomadores de preços na colocação dos produtos, eles enfrentam dificuldades para sobreviver e prosperar. Em outras palavras, uma espécie de bloqueio estrutural que acomete os pequenos produtores brasileiros, alcançaria grande parte dos assentados também. Se não se consegue viabilizar economicamente a maior parte dos pequenos produtores, mesmo quando se disponibiliza terra, créditos e ATER, qual seria o sentido de uma custosa política de novos assentamentos, questiona o autor.

\footnotetext{
20 autor se referia a uma espécie de ideologia que previa a construção de cidades baseadas em mudanças utópicas nos hábitos, modelos de vida e condutas morais, cuja resultante, somada a outros fatores, seria uma série de ações governamentais mal-sucedidas.
} 
Em reforço da decisão do INCRA de acelerar a titulação estava o entendimento que a falta da outorga dos títulos de domínio, exerce, ao mesmo tempo, uma proteção e uma clausura aos assentados. Sem o mesmo, não se consegue crédito bancário capaz de alavancar a sua produção. Por outro lado, a não concessão reduz o risco do assentado ser considerado inadimplente (Alves et al, 2015) (De Janvry, 2010).

Com a boa performance da economia brasileira, na primeira década do século XXI, houve aceleração na criação de assentamentos e diminuição do número de famílias acampadas, não necessariamente decorrente da criação de novos assentamentos, mas sim porque as oportunidades ocupacionais falavam mais alto. Mesmo que a demanda por terras tenha que ser sempre cotejada com oportunidades alternativas aos sem-terra, é muito provável que, no Brasil, a procura por assentamentos fosse também decorrente da expectativa de não pagamento ou, pelo menos, de alto subsídio a ser concedido aos assentados na liquidação da dívida pelo recebimento dos lotes, bens que giravam entre 100 e 200 mil reais, entregues, praticamente, sem ônus.

Essa percepção impulsionava a formação de acampamentos e condicionava a ação do INCRA à dinâmica dessa mobilização. Aparentemente, em 2012, os dirigentes do INCRA se deram conta dessa relação de funcionalidade. Mesmo com a alta taxa de desemprego da atualidade, há poucas pessoas acampadas, possivelmente, porque não se vislumbra a possibilidade de o INCRA atuar como antes.

Quanto à questão central do texto - o que teria levado à paralisação da reforma agrária, qual a determinante de última instância, a causa causarum (?) - há interpretações que, a despeito de reconhecerem os óbices orçamentários, explicam a paralisação como resultante da luta de classes. Assim, a correlação de forças estaria, momentaneamente, ao lado dos "ruralistas" e do "agronegócio", tido, ali, não como um setor da economia, mas como uma espécie de burguesia agrária. Demais, segundo esses argumentos, não defender a reforma agrária seria uma adesão às elites, uma mácula moral daqueles que não se preocupam com pobreza, desigualdade, ou mesmo, com o que seria visto como uma defesa dos setores conservadores, que teriam a “humilhação como recurso de poder" (Bruno, 2017, p. 166) e o "produtivismo" como estratégia econômica.

Estas assertivas, de algum modo, correm o risco de serem tautológicas, tornando a política autoexplicativa (se há concentração fundiária, então há questão agrária), negligenciando a preocupação com a pobreza e com a concentração da produção e renda no campo, contra as quais a reforma agrária não foi eficaz. A esfera dos que defendem a vigência da reforma agrária 
é bem mais amplo e contempla argumentos menos ideologizados como os da ressignificação e enfrentamento de um passivo social deixado pelo desenvolvimento agrícola recente.

De outro lado tem-se interpretações que consideram, a despeito dos esforços de diversas políticas públicas das últimas décadas, que a situação do produtor de pequeno porte econômico no Brasil vem se agravando e que insistir na reforma agrária, aparentemente, não seria o encaminhamento mais racional. O discurso dessa parcela da comunidade de pesquisadores do rural brasileiro, aponta para o fato da inserção no mercado por parte dessa categoria ser assimétrica e desvantajosa por serem menos competitivos, menos capitalizados e com menores conhecimentos técnicos. Parte deles vem abandonando a atividade para ingressar no mercado de trabalho formal ou informal, visando a garantia de renda. Isto acontece no interior dos assentamentos e fora deles, explicando, em parte, que malgrado o INCRA tenha assentado centenas de milhares de famílias entre os dois últimos censos agropecuários, não ocorreu desconcentração da posse da terra, como demonstra a tabela 3.

Os argumentos sinalizam que no período intercensitário, entre 2006 e 2017, o número de estabelecimentos agropecuários reduziu-se de 5.175.636 para 5.073.324, uma variação de pouca monta, enquanto o número de pessoas ocupadas nos mesmos diminuiu de 16.568.205 para 15.105.125 milhões, o que significa que 1.463 .080 pessoas deixaram de ter ocupação nos estabelecimentos agropecuários (IBGE, 2020b). Estes dados evidenciam que o número de assentados no mesmo período, cerca de 378.121 famílias, não compensou, em termos de postos de trabalho criados, a redução do número de pessoas ocupadas, provocada pelas mudanças demográficas e pela adoção de técnicas poupadoras de trabalho, entre outras razões, segundo Maia (2020).

Aduzem ainda esses pesquisadores que as maiores oportunidades externas ao meio rural explicam o porquê de o êxodo rural ter intensidade mais alta no Sul do que no Nordeste (Alves; Souza; Gomes, 2013). O mesmo raciocínio vale para o arrendamento de terras, bastante frequente nos assentamentos, não raro, resultando em conflitos pelo controle das terras e da água, a exemplo do arroz orgânico no Rio Grande do Sul (Mello, 2017; 2019b).

Essas abordagens chamam atenção para a semelhança entre o ocorrido na esfera dos assentamentos e o que sucede no setor agropecuário brasileiro como um todo: aumento da área média cultivada e concentração da produção agropecuária. Segundo Alves et al (2020), novas informações do Censo Agropecuário de 2017 ratificam o já observado no de 2006: o nível de concentração da renda bruta agrícola, em 2017, medido pelo índice de Gini com base na unidade 
censitária, é superior a $90 \%$, com menos de $1 \%$ dos estabelecimentos sendo responsáveis por $50 \%$ do valor total da produção.

Além disso, no Censo de 2006, da parcela de 9,5\% que produziam $86 \%$ da produção total, somente $11 \%$ dos estabelecimentos tinham mais de 500 hectares: há produtivos e improdutivos em todos os estratos de tamanho de terra (Helfand; Rada; Magalhães, 2017). Embora em alguns assentamentos, encontre-se êxito produtivo, inclusive no que tange à produção orgânica voltada para mercados institucionais e em comércio direto com faixas diferenciadas da população, desafortunadamente, representam um pequeno grupo.

Acrescenta-se no discurso dessa parcela da comunidade de pesquisadores do rural brasileiro o argumento que concentração de renda e terra não é um privilégio brasileiro. A diminuição do número de estabelecimentos rurais é uma tendência mundial, a exemplo da China (Monte; Lopes; Contini, 2017), da Índia (Seixas; Contini; Soares, 2018) e da França (Agarwal e Dorin, 2019). O número de estabelecimentos rurais na França, por exemplo, passou de mais de um milhão, em 1988, a menos de 500 mil, em 2010. Quanto à concentração de produção e renda, os números dos Estados Unidos e Europa são compatíveis com os do Brasil (Alves; Souza; Gomes, 2013).

Com efeito, esta concentração explica a redução da participação da agricultura familiar no valor bruto da produção, VBP, que foi de 38\% em 2006 e, 11 anos depois, em 2017, passou para 23\% (IBGE, 2020b). Contudo, esta redução pode ter sido menor, caso o IBGE utilizasse o conceito universal de agricultura familiar baseado na gestão da família. ${ }^{3}$ Entretanto, para o IBGE, na categoria de agricultura familiar estariam, somente, os estabelecimentos agropecuários com área inferior a quatro módulos fiscais. Este critério exclui os estabelecimentos com gestão familiar que não são patronais e que se destacam por escala de produção e renda gerada. São estabelecimentos efetivamente familiares do ponto de vista da gestão e que lograram, com o uso intensivo de tecnologia, preservar a gestão familiar e limitar a contratação de mão de obra assalariada (Hoffmann, 2014) (Baiardi, 2004) (IBGE, 2020b).

\footnotetext{
${ }^{3}$ O IBGE adota a definição do artigo 3 da Lei 11.326/2006 que define agricultura familiar como limitada em área até 4 módulos fiscais. Esta definição é mais restritiva que o conceito da Food and Agricultural Organization, FAO, segundo a qual parte dos produtores brasileiros são efetivamente familiares, embora operam em uma escala mais próxima da agricultura patronal.
} 


\section{Considerações finais: como avançar no debate}

Mesmo admitindo que o INCRA pudesse ter seu orçamento multiplicado e fosse eficiente do ponto de vista administrativo, ainda assim, aparentemente, não teria condições de alterar a tendência de transformação da agropecuária brasileira, com sua face excludente. Todas essas evidências, entre elas os dados do Censo Agropecuário de 2017 e o aumento do custo da reforma agrária, cotejados com a fraca resposta produtiva dos assentamentos, sugerem que ao nível do INCRA, por convicção ou por imposição, estabeleceu-se uma situação de compliance corporativo, razão de Estado, com uma avaliação tácita de que não faria sentido continuar investindo tantos recursos numa política agrária, recursos estes que faltam nas políticas de apoio aos agricultores de pequeno porte, que enfrentam dificuldades para sobreviver mantendo-se na atividade.

Nesse sentido, é possível que a paralisação da reforma agrária não se deva a um bloqueio promovido pela Frente Parlamentar da Agricultura, ou a uma manobra neoliberal de parte das forças produtivas "retrógradas," ou mesmo a uma "conspiração" em prol do agronegócio, como aludem Firmiano e Oliveira (2018) e Nakatani et al (2012). Lembrando que em gestão governamental anterior, até 2003 , tida por muitos como neoliberal, a reforma agrária teve números significativos, equivalentes aos obtidos nos períodos subsequentes, até 2010.

As visões analisadas no presente trabalho, grosso modo, convergem quanto à necessidade de intervenções públicas para corrigir a concentração da renda e a pobreza rural no Brasil, mas divergem quanto ao papel da distribuição de terra como parte da política agrária. Esta, segundo Hoffmann ${ }^{4}$ (2020), perdeu capacidade de atuar na redução da concentração da terra e, de acordo com Baiardi e Costa (2020), não respondeu por maior eficiência produtiva no Semiárido onde se localizam a maioria dos assentamentos do Nordeste.

Inequivocamente, o campo vem envelhecendo, se masculinizando e parte da agricultura familiar vem regredindo para situação de autoconsumo, com menos pessoas ocupadas em atividades agrícolas e com mais residentes ocupados em atividades não agrícolas, muitos sobrevivendo de aposentadorias rurais (Del Grossi, 2017). A parcela que ainda deverá abandonar a agropecuária não representa mais um volume com poder de provocar um "inchaço" urbano em cidades maiores. Aliás, as migrações têm ocorrido para as cidades de porte médio (Maia,

\footnotetext{
4 "Foram revistos trabalhos que mostram que a desigualdade da distribuição da posse de terra nas microrregiões do Brasil está negativamente associada com o respectivo desenvolvimento humano. Contudo, ressaltou-se que isso não significa que a reforma agrária seja o único ou principal caminho para promover esse desenvolvimento" (Hoffmann, 2020, p.89)
} 
2020). Portanto, já não há uma questão demográfica. De outro lado, há no Brasil programas de renda mínima e de habitação que cumprem, vantajosamente, um papel compensatório de uma reforma agrária que não logra se destacar na emancipação econômica de agricultores assentados.

Em abordagem internacional, visando definições de uma nova agenda de pesquisas sobre o rural, suas transformações e as tendências de desenvolvimento, pesquisadores chamam atenção para a necessidade de se estudar novas ruralidades em um mundo menos rural, mesmo tendo abstraído o exemplo das "fazendas urbanas" ${ }^{5}$ da Holanda e da Dinamarca, que trazem novos ingredientes para o debate (Marsden; Lamine; Schneider, 2020).

Em sendo a reforma agrária muito dispendiosa - de acordo com Santana e Silva (2018) o custo médio por família assentada, levando em conta exclusivamente as despesas de desapropriação e aquisição, foi estimado em cerca de $\mathrm{R} \$ 218.000,00$-, não é razoável persistir investindo recursos vultuosos em futuros assentamentos. Diante de quase quatro milhões de agricultores familiares, em grande parte com imensa demanda por infraestrutura, capacitação e assistência técnica, a reforma agrária perde prioridade.

Como lembrado por Mello (2016b), apoiado em Muller (1984), durante a década de 1960, o Estado francês compreendeu a inevitabilidade de dois processos: a modernização da agricultura e o êxodo rural. A decisão de apoiar a modernização de jovens agricultores proprietários de áreas médias e, em paralelo, oferecer condições financeiras e de capacitação para humanizar a saída da agricultura, se mostrou acertada.

$\mathrm{Na}$ linha de sugestões para avançar nos debates sobre a paralisação da reforma agrária, conviria se dar maior importância à necessidade de equilíbrio fiscal, conduta de gestão macroeconômica imprescindível a qualquer governo, independente das visões de mundo. Em segundo lugar, buscar mais rigor metodológico e menos viés ideológico e transposições mecânicas de categorias e conceitos. Recorrer a uma abordagem inspirada na acumulação primitiva descrita por Marx no século XIX, que tem no enclosure act inglês o caso emblemático de expropriação de terras, para tentar explicar a contemporaneidade brasileira no concernente a uma exigência de capital seminal para financiar o agronegócio, não parece adequado.

No atual contexto brasileiro, até mesmo utilizando a categoria de acumulação por desapossamento de Harvey (2013), se percebe, claramente, que o capital seminal na agropecuária tem outras fontes, diferentes da expropriação de pequenos agricultores, sejam elas

5 Urban Farming with Hydroponics - (2021) 
outros segmentos do agronegócio ou mesmo os incentivos governamentais a grandes grupos do oligopólio da indústria alimentar. Por fim, ressalta-se a necessidade de continuar o debate com despojamento de ideias preconcebidas e de valores inarredáveis e com esforços de considerar o fenômeno na sua totalidade.

\section{Referências}

ABRA, Associação Brasileira de Reforma Agrária, (2020). Lista dos sumários das Revistas da ABRA (1971 a 2014). Recuperado em 14 mar. 2020 em:

http://www.reformaagrariaemdados.org.br/biblioteca/revistas/lista-dos-sumarios-das-revistasda-abra-1971-2007

AGARWAL, B.; DORIN, B. (2019) Group farming in France: Why do some regions have more cooperative ventures than others? Environment and Planning A: Economy and Space, 51(3), 781-804.

ALENTEJANO, P. A (2018) Política agrária do governo Temer: a pá de cal na agonizante reforma agrária brasileira. Revista OKARA: Geografia em debate, 12 (2), 308-325.

ALMEIDA, M. B., AMIN, M. M.; SOUZA FILHO, T. A. (2009) Reforma Agrária e modernização da agricultura: contribuições para a avaliação da experiência brasileira. Revista de Administração e Negócios da Amazônia 1(1), 32-50.

ALVES, E.; SOUZA, G. S.; ROCHA, D. P. (2006) Desigualdade nos campos na ótica do Censo Agropecuário. Revista de Política Agrícola, 22 (2), 67-75.

ALVES, E. A.; SOUZA, G. S.; GOMES, E. G. (2013) Contribuição da Embrapa para o desenvolvimento da agricultura no Brasil. Editores técnicos. Brasília, DF: Embrapa.

ALVES, E. A.; SANTANA, C. A. M.; CONTINI, E. (2016) Extensão rural: seu problema não é a comunicação. In: VIEIRA FILHO, J.E.R.; GASQUES, J.G. (Org.). Agricultura, transformação produtiva e sustentabilidade (p.65-86). Brasília: Ipea.

ALVES, E.; SOUZA, G. S.; GOMES, E. G. A (2020) Concentração do valor bruto da produção e a pobreza segundo o Censo Agropecuário 2017. In: NAVARRO, Z. (org.). A economia agropecuária do Brasil. A grande transformação (p.176-182). São Paulo: Editora Baraúna.

BAIARDI, A. (2004) Desenvolvimento rural e consolidação da moderna agricultura familiar no Oeste Baiano: de colonos a neo-farmers. Bahia Análise \& Dados, 13(4), 951-967.

BAIARDI, A.; COSTA, E. M. (2020) Solução produtiva para o Nordeste In: VIEIRA FILHO, J.E.R.; GASQUES, J. G. Uma jornada pelos contrastes do Brasil: Cem anos do Censo Agropecuário ( $p$ 135-148). Brasília: IPEA/IBGE/MAPA.

BARONE, L. A.; FERRANTE, V. L. S. B. (2017) Reforma agrária no Brasil do século XXI: bloqueios e ressignificações. In: DELGADO, G.C.; BERGAMASCO, S. M. P. P. Agricultura Familiar Brasileira: Desafios e Perspectivas de Futuro, (p. 22-39). Brasília: Ministério do Desenvolvimento Agrário.

BRUNO, R. (2012) Guardiões da reforma agrária: Servidores públicos e técnicos em defesa de uma reforma agrária durante a ditadura militar do Brasil. Tempos Históricos, 16 (2), 71-97.

(2017) Bancada ruralista, conservadorismo e representação de interesses no Brasil contemporâneo. In: MALUF, R.; FLEXOR, G. (Org.) Questões agrárias, agrícolas e rurais: conjunturas e políticas públicas (p.155-168), 1. ed. - Rio de Janeiro, E-Papers, 2017. 
CARFANTAN, J. Y. (2020) Illusions et impasses de la réforme agraire. Recuperado em 24 março de 2020 em: https://www.istoebresil.org/post/illusions-et-impasses-de-la-r\%C3\%A9formeagraire-6

COLLINS, H. M. (1992) Changing order: Replication and induction in scientific practice. Chicago: University of Chicago Press.

COLLINS, H. M. (Ed.) (1981). Knowledge and controversy: Studies of modern natural science. Newbury Park, CA: Sage Publications.

DAVID. M. B. A; WANIEZ, P.; BRUSTLEIN, V. (1998) Situação social e demográfica dos beneficiários da reforma agrária: um atlas. Brasília: Texto para Discussão, IPEA.

DE JANVRY, A. (2010) Agriculture for development: new paradigm and options for success. Agricultural Economics, 41(S1), 17-36.

DELGADO, G. C. (2005) A questão agrária no Brasil, 1950-2003. In: IPEA. Questão social e políticas sociais no Brasil contemporâneo (p. 51-90). Brasília: IPEA.

. (2014) Questão agrária hoje. Revista da ABRA, Ano 35 1(2), 27-40.

DEL GROSSI, M. E. Agricultura familiar e a nova ruralidade entre 2004 a 2014. In: MALUF, R.;

FLEXOR, G. (Orgs.) Questões agrárias, agrícolas e rurais: conjunturas e políticas públicas (p.257268), 1. ed. - Rio de Janeiro, E-Papers, 2017.

FIRMIANO, F. D.; de OLIVEIRA M. K. C. (2018). A reforma da contrarreforma agrária no Brasil/The reform of the agrarian counter-reform in the Brazil. Libertas, 18 (2), 33-48.

FLEXOR, G; LEITE, S. (2017) Mercado de terra, commodities boom e land grabbing no Brasil. In: MALUF, R.; FLEXOR, G. (Orgs.) Questões agrárias, agrícolas e rurais: conjunturas e políticas públicas (p.20-38), 1. ed. - Rio de Janeiro, E-Papers.

GASQUES, J. G.; CONCEIÇÃO, J. C. P. R. (2000) A demanda de terra para a reforma agrária no Brasil. In: LEITE, P. S. et al (Orgs.). Reforma agrária e desenvolvimento sustentável (p.67-98) Brasília: Paralelo 15/Núcleo de Estudos Agrários e Desenvolvimento, Ministério do Desenvolvimento Agrário.

GOMES da SILVA, J. (1971) A reforma agrária no Brasil: frustração camponesa ou instrumento de desenvolvimento. Rio de Janeiro: Zahar.

(1982) A modernização dolorosa: Estrutura Agrária, fronteira agrícola e trabalhadores rurais no Brasil. São Paulo: Hucitec.

Vida.

. (1987) Caindo por terra: crises da reforma agrária na Nova República. São Paulo: Busca

(1989) Buraco negro: a reforma agrária na constituinte. Rio de Janeiro: Paz e Terra.

GRAZIANO NETO, F. (1989) A verdade da terra: crítica da reforma agrária distributivista. Tese de Doutorado defendida em 1989. São Paulo: FGV.

. (2004) O carma da terra no Brasil. São Paulo: A Girafa.

. (1994) Recolocando a questão agrária. In: STÉDILE, J. P. (org.). A questão agrária hoje (p. 238-254). Porto Alegre: Ed. da Universidade/UFRGS.

GRAZIANO NETO, F.; NAVARRO, Z. (2015) Novo mundo rural, a antiga questão agrária e os caminhos futuros da agropecuária no Brasil. São Paulo: Editora UNESP.

HARVEY, D. (2013) Para entender o capital. Ed. Boitempo. 
HELFAND, S.; RADA, N. E.; MAGALHÃES, M. M. (2017) Brazilian Agriculture: Is it all about the Large Farms? Euro Choices, 16 (1), 17-22.

HOFFMANN, R. (2014) A agricultura familiar produz 70\% dos alimentos consumidos no Brasil? Segurança Alimentar e Nutricional 21(1), 417-421.

. (2020) A distribuição da posse de terra no Brasil (1985-2017) In: VIEIRA FILHO, J.E.R.; GASQUES, J. G. Uma jornada pelos contrastes do Brasil: Cem anos do Censo Agropecuário ( $p$ 77-90). Brasília: IPEA/IBGE/MAPA.

IBGE. (2020a) Censo demográfico. 1940-2010. Recuperado em 27 de fevereiro de 2020 em: https://seriesestatisticas.ibge.gov.br/series.aspx?vcodigo=POP122

. (2020b) Censo agropecuário de 2017. Recuperado em 22 de fevereiro de 2020 em: https://www.ibge.gov.br/estatisticas/economicas/agricultura-e-pecuaria/21814-2017-censoagropecuario

INCRA (2020) Números da Reforma Agrária, Execução Anual, Famílias Assentadas, Área Incorporada por Exercício. Recuperado em 27 de janeiro 2021 em http://antigo.incra.gov.br/pt/numeros-reforma-agraria.

. (2021) Reforma Agrária. Recuperado em 28 de janeiro 2021 em:

http://antigo.incra.gov.br/pt/reforma-agraria.html.

KUHN, T. S. (1970) The structure of scientific revolutions. Chicago: The University of Chicago Press.

LACERDA, A. G.; MALAGODI, E. (2007) Formas de cooperação e reforma agrária. Raízes, Campina Grande, 26 (1 e 2), 93-100, jan./dez.

MAIA, A.G. (2020) Mudanças Demográficas no Rural Brasileiro de 2006 a 2017. In: VIEIRA FILHO, J.E.R.; GASQUES, J. G. Uma jornada pelos contrastes do brasil: Cem anos do Censo Agropecuário (p. 67-75). Brasília: IPEA/IBGE/MAPA.

MARSDEN, T; LAMINE, C.; SCHNEIDER, S. (2020) Introduction to A Research Agenda for Global Rural Development In: STOREY, D. (Ed.). A Research Agenda for Territory and Territoriality (p. 1-6). Cheltenham: Edward Elgar Publishing.

MARTINS, J. S. (2003) A reforma agrária no segundo mandato de Fernando Henrique Cardoso. Tempo social, v. 15, n. 2, p. 141-175.

MARQUES, M. I. M. (2011). O novo significado da questão agrária. In: Anais do V Simpósio Internacional de Geografia Agrária VI Simpósio Nacional de Geografia Agrária -SINGA (p. 302326). Belém: UFPA,

MATTEI, L. (2012) A reforma agrária brasileira: evolução do número de famílias assentadas no período pós-redemocratização do país. Estudos Sociedade e Agricultura, 20 (1), 301-325.

. (2014a) Teses favoráveis e contrárias à reforma agrária brasileira no limiar do século XXI. Revista da ABRA, Ano 35 1(2), 93-112.

. (2014b) Considerações Acerca de Teses Recentes sobre o Mundo Rural Brasileiro.

Revista de Economia e Sociologia Rural, 52 (1), S105-S124.

- (2016) O debate sobre a reforma agrária no contexto do Brasil rural atual. Política \& Sociedade, Florianópolis, v. 15, Edição Especial, 234-260.

MELLO, P. F. (2016a) As impossibilidades da reforma agrária brasileira. Revista de Política Agrícola, 25 (1), 108-121. 
. (2016b) Assentamentos rurais no Brasil: uma releitura. Brasília, DF: Embrapa, (Texto para Discussão, 45).

. (2017) Mediadores da pobreza e a pobreza dos mediadores. Revista de Política Agrícola, ano 26 (4), 104-117.

. (2019a) Problematizando a cooperação Incra-Embrapa. Revista de Política Agrícola, ano $28(3), 55-80$.

. (2019b) Organic rice in settlements of Rio Grande do Sul: a broken artefact. Revista de Política Agrícola, 28 (2), 103-121.

. (2020) Lógicas de ação no serviço público: uma análise plural do Incra. Porto Alegre:

edição do autor.

MONTE, D. C.; LOPES, D. B.; CONTINI, E. (2017) China: Nova potência também no agronegócio.

Revista de Política Agrícola, 26(3), 107-123.

MULLER, P. (1984) Le technocrate et le paysan: essai sur la politique française de modernization de l'agriculture, de 1945 à nos jours. Paris: Ouvrières.

NAKATANI, P.; FALEIROS R. N.; VARGAS, N. C. (2012) Histórico e os limites da reforma agrária na contemporaneidade brasileira Serviço Social Sociedade. (110), 213-240.

NAVARRO, Z. (1997) Sete teses equivocadas sobre as lutas sociais no campo - o MST e a reforma agrária. São Paulo em Perspectiva, 11 (2), 86-93.

. (2010) A agricultura familiar no Brasil: entre a política e as transformações da vida econômica. In: Embrapa Estudos e Capacitação (pp 187-209). Brasília: EMBRAPA.

. (2011) A vida e os tempos da Questão Agrária no Brasil. In: TEIXEIRA, E. C.; MATTOS, L. B. de; LEITE, C. E. (Ed.). As questões agrária e da infraestrutura de transporte para o agronegócio (pp. 85-112). Viçosa, MG: Ed. da UFV: DER.

. (2014) Por que não houve (e nunca haverá) reforma agrária no Brasil. In: BUAINAIN, A.; ALVES, E., SILVEIRA, J. M; NAVARRO, Z. O mundo rural no Brasil do século 21 (pp. 695-724). Campinas: EMBRAPA/UNICAMP.

. (2016) The rise and fall of land reform in Brazil: A tale in three acts. Revista de Política Agrícola, 25 (3), 36-51.

. (2019) Meio século de interpretações sobre o rural brasileiro (1968-2018). Revista de Economia e Sociologia Rural, 57(3), 472-489.

POPPER, K. Lo scopo della scienza. Roma: Armando Editore, 2000.

RIBEIRO, M. M. C; NETO, J. A. F; DIAS, M. N.; FIÚZA, A. L. C. (2011) Análise das causas da evasão em assentamentos de reforma agrária no Estado do Tocantins. Revista Extensão Rural, DEAER/PPGEXR (22), 103-132.

SANTANA, E. B.; SILVA, J. O. (2018) Política fundiária: uma análise sobre a criação de novos assentamentos de reforma agrária no Brasil. In: Anais da VIII Semana de Economia, Políticas Públicas para o Desenvolvimento, Ilhéus: UESC, Recuperado em 22 de dezembro de 2020 em: http://www.uesc.br/eventos/viiisemeconomia/anais/gt1/gt1_t6.pdf.

SCOTT, J. C. (2020) Seeing like a state: How certain schemes to improve the human condition have failed. Yale: Yale University Press.

SEIXAS, M.; CONTINI, E.; SOARES, C. O. (2018) Índia: o despertar de um gigante do agronegócio. Revista de Política Agrícola, 27(3), 95-113. 
SILVA, J. G da (1998) Políticas Não Agrícolas para o Novo Rural Brasileiro. In: AGUIAR, D.; PINHO, JB O agronegócio brasileiro: desafios e perspectivas, (p. 117-142). Brasília: Edições Sober, v. 1,

(2013) Por uma reforma agrária não essencialmente agrícola. In: STÉDILE, J. P.; ESTEVAM, D. A Questão Agrária no Brasil: Debate Sobre a Situação e Perspectivas da Reforma Agrária na Década de 2000 (p 69-86). São Paulo: Editora Expressão Popular.

SPAROVEK, G. (2003) A qualidade dos assentamentos da reforma agrária brasileira. São Paulo: Páginas \& Letras Editora e Gráfica.

TREVISAN, A. P.; VAN BELLEN, H. M. (2008) Avaliação de políticas públicas: uma revisão teórica de um campo em construção. Revista de Administração Pública, 42 (3), 529-550.

URBAN FARMING WITH HYDROPONICS (2021) Recuperado em 29 de abril de 2021 em: http://www. the-urban-farmer.co.uk/hydroponics.html.

VEIGA, J. E. (2003) Cidades imaginárias: o Brasil é menos urbano do que se calcula. 2. ed. Campinas: Autores Associados. 